\title{
Towards Implementing Gamification in MOOCs
}

\author{
Citation for published version (APA):
}

Antonaci, A., Klemke, R., Stracke, C. M., \& Specht, M. (2017). Towards Implementing Gamification in MOOCs. In J. Dias, P. A. Santos, \& R. C. Veltkamp (Eds.), Games and Learning Alliance: 6th International Conference, GALA 2017, Lisbon, Portugal, December 5-7, 2017, Proceedings (pp. 115-125). Springer. Lecture Notes in Computer Science Vol. 10653 https://doi.org/10.1007/978-3-319-71940-5_11

\section{DOI:}

10.1007/978-3-319-71940-5_11

Document status and date:

Published: 01/11/2017

Document Version:

Peer reviewed version

\section{Document license:}

CC BY-NC-ND

Please check the document version of this publication:

- A submitted manuscript is the version of the article upon submission and before peer-review. There can be important differences between the submitted version and the official published version of record. People interested in the research are advised to contact the author for the final version of the publication, or visit the DOI to the publisher's website.

- The final author version and the galley proof are versions of the publication after peer review.

- The final published version features the final layout of the paper including the volume, issue and page numbers.

Link to publication

\section{General rights}

Copyright and moral rights for the publications made accessible in the public portal are retained by the authors and/or other copyright owners and it is a condition of accessing publications that users recognise and abide by the legal requirements associated with these rights.

- Users may download and print one copy of any publication from the public portal for the purpose of private study or research.

- You may not further distribute the material or use it for any profit-making activity or commercial gain

- You may freely distribute the URL identifying the publication in the public portal.

If the publication is distributed under the terms of Article 25fa of the Dutch Copyright Act, indicated by the "Taverne" license above, please follow below link for the End User Agreement:

https://www.ou.nl/taverne-agreement

Take down policy

If you believe that this document breaches copyright please contact us at:

pure-support@ou.nl

providing details and we will investigate your claim.

Downloaded from https://research.ou.nl/ on date: 26 Apr. 2023 
Antonaci A., Klemke R., Stracke C.M., Specht M. (2017) Towards

Implementing Gamification in MOOCs. In: Dias J., Santos P.,

Veltkamp R. (Eds) Proceedings of Games and Learning Alliance

conference. GALA 2017. Lecture Notes in Computer Science, vol

10653. Springer, Cham

https://doi.org/10.1007/978-3-319-71940-5 11

\title{
Towards Implementing Gamification in MOOCs
}

\author{
Alessandra Antonaci', Roland Klemke', Christian M. Stracke', Marcus Specht' \\ ${ }^{1}$ Welten Institute - Research Centre for Learning, Teaching and Technology, Open \\ University of the Netherlands, P.O. Box 2960, 6401 DL Heerlen, The Netherlands \\ \{alessandra.antonaci, roland.klemke, christian.stracke, \\ marcus.specht\}@ou.nl
}

\begin{abstract}
Gamification is well known as a design strategy used to generate a change in users' behaviour, such as motivation. However, while in recent years interest in it has been growing, empirical evidence on the effects that the application of game elements can generate on users' behaviour is still lacking. We present the results of a study as a step towards designing gamification with better understanding of the possible effects that each game element could generate on end users. By involving three groups of experts: game designers, learning scientists and specialists in technology-enhanced learning (TEL), we assessed a selected number of 21 game design patterns in relation to the effects these could generate on learning performance, goal achievement and engagement of learners if implemented in a Massive Online Open Course (MOOC). Based on quantitative and qualitative data collected, 9 game elements have been selected to be further investigated.
\end{abstract}

\section{Introduction}

In the last 10 years, gamification has been applied in several fields, such as: marketing, trading, training, fitness, software engineering, etc. The highest number of applications can be found in education [1] [2]. "Education is a fundamental human right and essential for the exercise of all other human rights. It promotes individual freedom and empowerment and yields important development benefits" [3]. With the aim of bringing education to all, phenomena such as Open Education and in particular MOOCs have started to grow in recent years.

MOOCs, taking advantage of the Internet, could hypothetically bring knowledge to everyone and for free. Despite this potential, MOOC studies have highlighted several limits, such as the lack of users' engagement and their high dropout rate [4]. To overcome these gaps our idea is to apply gamification in MOOC to enhance users' goal achievement, engagement and also impact on users' learning performance.

Conceptual examples of gamification applied in MOOC environments can be found as detailed in [4]. A first attempt at raising awareness on gamification by empirical evidence can be found in [5], where 40 suitable game mechanics to engage students in MOOCs were identified and rated by 5,020 participants through an online survey for their level of engagement. Among the 40 selected, 10 game mechanics were evaluated with the highest level of engagement (virtual goods; three different types of points; leader boards; trophies and badges; peer grading and emoticon feedback; two types of games) by users. The engagement level of these mechanics was defined based on users' self-perception, not on an empirical basis and space was not given to the designers' point of view. Which effects did the designers aim to 
stimulate in users? Did the perception of users match with the intention of the designers? With the purpose of testing this relationship between designers' intention and effects on users' behaviour and perception, in this paper we present our first step towards implementing gamification in MOOCs by involving three groups of experts that are invited to evaluate a selection of game design patterns ${ }^{1}$ (GDPs) for their suitability in a MOOC application.

The three groups of experts come from different but complementary fields: (1) game design, from them we expected the ability to evaluate the effects of specific GDPs in a given scenario from a game perspective; (2) learning science, who could judge the GDPs from a didactic and educational perspective; and (3) the TEL field who can evaluate both perspectives and rate applicability and feasibility of the GDPs chosen. Each group of experts assess each of the 21 available GDPs from their perspective in accordance with the scenario of application (MOOC) and one of the following purposes of intervention: p1- enhancing MOOC users' learning performance via gamification; p2- enhancing MOOC users' goal achievement and p3enhancing MOOC users' engagement.

The 21 GDPs chosen come from Björk and Holopainen's collections [6]. These were selected in accordance with the following criteria (1) the frequent use of a GDP in the literature, (2) the applicability of a GDP in a multi-user environment, and (3) our hypothesised impact of the selected patterns on learners' engagement, goal achievement, or learning performance. As a result, the following GDPs were presented to 42 experts to be validated:

1. Avatars/Characters, that are "abstract representations of the person".

2. Time Limit, it can be related to action completion or goal achievement.

3. Levels: "a level is a part of the game in which all players' actions take place until a certain goal has been reached or an end condition has been fulfilled".

4. Communication Channels, "are the medium and the methods players can use to send messages to other players".

5. High Score Lists, display players' rank and give them the chance to compare themselves against other players "who have previously played the game".

6. Score, "is the numerical representation of the player's success in the game".

7. Status Indicators, via them users can gain information about "a certain part of the game state or other players".

8. Public Information, is information of the game state "available during the game to people other than the players".

9. Storytelling, the act of telling stories within the game.

10. Rewards, the player receives something for completing goals or levels in the game.

11. Goal Indicators, give information to players about their current goals in the game.

12. Stimulated Planning, enables users to plan certain aspects or actions in the game.

${ }^{1}$ In this paper the term game elements, game mechanics and game design patterns are used as synonyms even if the authors are aware of their differences. In particular, game elements are attributes of a game (such as score), while game mechanics are "any part of the rule system of a game that covers one, and only one, possible kind of interaction that takes place during the game" [8]. As for Game Design Pattern, (GDP), "The origin of the concept of "design patterns" hails from the field of architecture and in particular was coined by Christopher Alexander" [9]. Applying GDP is also a method of codifying game design knowledge in separate but interrelated parts. 
13. Clues, "are game elements that give the players information about how the goals of the game can be reached".[6][6]

14. Cooperation, "i.e. coordinate their actions and share resources, in order to reach goals or sub-goals of the game".

15.Limited Planning Ability, implies that players do not have all the information.

16. Competition, "is the struggle between players or against the game system to achieve a certain goal".

17. Team Play, "Players in a group or a team coordinate their actions, abilities, and roles in order to reach a common goal".

18. Replayability, enables a re-doing of the game or level.

19. Smooth Learning Curves, enable the chance to "smoothly progress from novice to master".

20. Handicaps, enable the chance to provide an easier gameplay in order to make all players have the same chance of succeeding.

21.Empowerment, "Players feel that they can affect the events and the final outcome of a game" [6].

\section{Study}

Procedures. Participants were introduced to "MOOCs" and "Gamification". The game designers were invited to take part in the focus group as part of a game design workshop and were divided into six groups assigned to the three intervention purposes p1-p3 (two groups for each purpose). These three purposes were identified in accordance with a literature review study related to MOOCs gaps. They are interdependent from each other and were settle to facilitate the participants' conceptualization. The topic of the MOOC was predefined as cyber-security. Each group elaborated a concept that was presented to the other colleagues. All participants filled out the survey, comprising 2 questions for each of the 21 GDPs selected: a closed question, rating the GDPs in relation to the purpose selected (p1-p3) using a scale from 0 ("strongly negative effect") to 4 ("strongly positive effect"). The second question for each GDP was optional and open; here participants could detail the advantages and/or disadvantages of using the given GDP for the specific purpose.

Methods. Two methods were used to assess the GDPs selected for the gamification design of a MOOC: a survey and a focus group. The survey was designed with the aim of validating our GDP selection and collecting feedback from our target population. Using a scale from 0 (strongly negative effects) to 4 (strongly positive effects), participants were asked to rate a total of 21 game elements. The game elements proposed to our audience population were rated in accordance with a specific scenario of application and a given purpose. The application scenario was a MOOC while the purpose of the intervention could be chosen from the following options: Enhancing users' learning performance via gamification (p1); Enhancing users' goal achievement via gamification (p2); Enhancing users' engagement via gamification (p3). Secondly, the focus group was designed and conducted for game designers with the aim of inviting them to conceptualise a gamified MOOC using the game elements that they deemed most relevant for one of the specific MOOC purposes given (p1-p3). The subjects could independently decide on which of the three gamification purposes of the intervention they wanted to focus (p1-p3)

Participants. A total of 42 subjects took part in our study, they come from different backgrounds and fields: 17 game design experts; 9 learning scientists and 16 TEL 
experts. Table 1 presents an overview of participant personal details and distribution among the purposes chosen.

Table 1- Sample distribution and details

\begin{tabular}{lccc}
\hline & Game Designers & Learning Scientists & TEL experts \\
\hline Age range per group & 18-24 years & 25-34 years & 25-34 years \\
\hline $\begin{array}{l}\text { P1- enhancing MOOC users' } \\
\text { learning performance }\end{array}$ & 6 (out of 17) & 4 (out of 9) & 5 (out of 16) \\
$\begin{array}{l}\text { P2 - enhancing MOOC } \\
\text { users' goal achievement }\end{array}$ & 6 (out of 17) & 3 (out of 9) & 4 (out of 16) \\
$\begin{array}{l}\text { P3- enhancing MOOC users' } \\
\text { engagement }\end{array}$ & 5 (out of 17) & 2 (out of 9) & 7 (out of 16) \\
\hline
\end{tabular}

The level of awareness of the two concepts: "gamification" and "MOOC" was also investigated and among the game designers 2 of them had followed one MOOC previously and they had all heard about gamification before. For the learning scientists, one of them had designed a MOOC, 3 (out of 9) had participated in one MOOC before and 1 (out of 9) in more than one MOOC, one of them had heard about gamification before. As for the TEL experts 2 (out of 16) had designed a MOOC before, 4 (out of 16) had followed one MOOC previously, 10 (out of 16) had followed more than one MOOC and 2 (out of 16) none. All had "heard about gamification before".

\section{Results}

\subsection{Quantitative Data}

In this section, we present the data collected with the questionnaire divided into three sub-sections, according to the participant audience. Starting with the Game design experts' evaluation Fig. 1 represents a summary of how the experts in game design rated the selected GDPs in accordance with the effects they expected related to the three purposes identified (p1 - p3) of our gamified intervention within a MOOC.

More in detail, with respect to $\mathrm{p} 1$, the GDPs most ranked are: Communication Channels with average score of 3.83; Levels average 3.67, and with equal score and average 3.5 Cooperation, Replayability and Smooth Learning Curves. The lowest score is Time Limits with a mean value of 1.5 , which considering the scale used allocates this GDP under the "neutral effect" (2) closer to the range "negative effect" (1). 


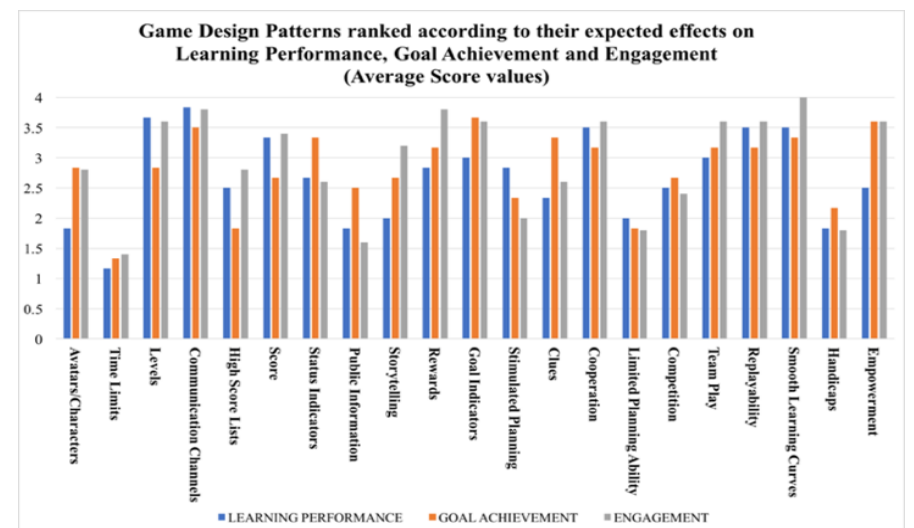

Fig.1 Representation of the GDP average values rated by game designers according to their expected effects on p1 (blue), p2 (orange) and p3 (grey) within a MOOC.

With respect to p2 (goal achievement), the highest ranked GDPs by the game designers are: Goal Indicators with an average score of 3.67, Empowerment, average 3.6, and Communication Channels, average 3.5. It needs to be underlined that none of the top 10 GDPs with high mean values was scored with 0 (strongly negative effects). Rating GDP effects on p3 (engagement), the GDPs with the highest average scores received are: Smooth Learning Curves with an average of 4, Communication Channels and Reward both with an average score of 3.8 and as for the other two purposes detailed, Time Limits registered the lowest average score of 1.4.

The learning scientists' evaluation. Among the learning scientists, the highest number (4 out of 9) chose to express their point of view on p1(learning performance), while the rest evaluated p2 (goal achievement) (3 out of 9) and p3 (engagement) (2 out of 9). With respect to p1, the learning scientists assigned the highest score to the following GDPs: Levels with average score of 4; Empowerment, average 3.75, and with equal score and average 3.5 Avatar/ Characters, Storytelling and Clues. For p2, the highest ranked GDPs are Smooth Learning Curves, average score 4 and the equally scored Clues and Empowerment, average 3.67. Looking at p3, the learning scientists evaluate the following GDPs with an average score of 4: Storytelling, Clues and Empowerment.

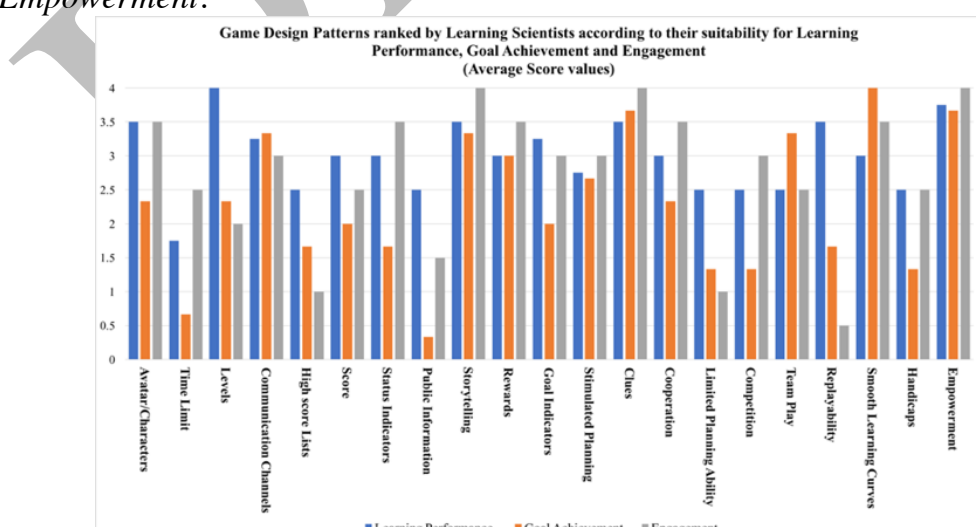

Fig. 2- Representation of the GDP average values rated by learning scientists related to p1 (blue), p2 (orange) and $\mathrm{p} 3$ (grey)

The TEL experts' evaluation. As shown in Fig. 3, the TEL experts (5 out of 16) evaluated the following GDP effects on 1 with the highest score: Levels and Smooth 
Learning Curves both with an average score of 3, and with equal score and average of 2.8: Storytelling, Replayability and Empowerment. Four participants selected p2 and according to their evaluation, the GDPs with highest scores were: Goal Indicators with an average score of 4; Levels, average 3.5, and, with equal score Replayability and Smooth Learning Curve with an average of 3.25. With respect to gamifying a MOOC to enhance users' engagement (p3), the GDPs that collected the highest scores are Communication Channels, Score, Goal Indicators, Cooperation and Smooth Learning Curve, all with the same average score of 3.43 .

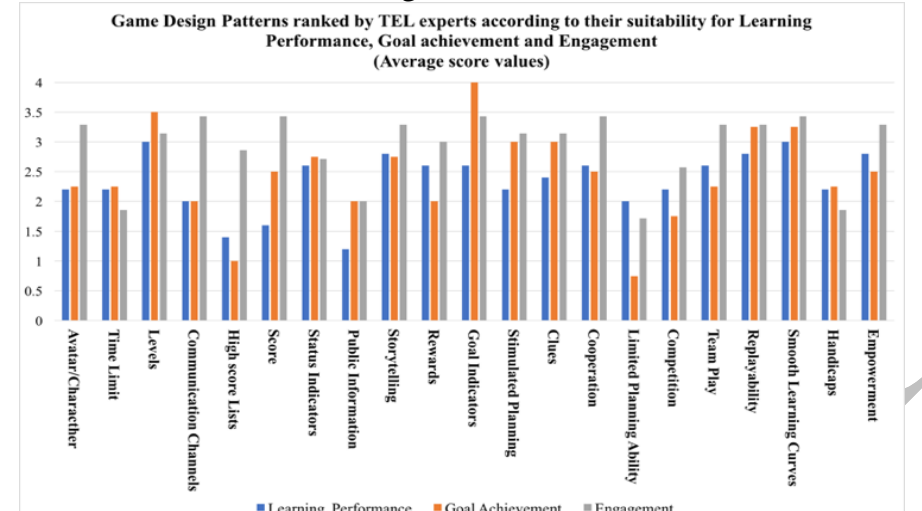

Fig. 3- Representation of GDP average values rated by the TEL Experts related to p1 (blue), p2 (orange) and $\mathrm{p} 3$ (grey)

\subsection{Qualitative Analysis}

Hints from Game Designers. Each group of game designers was invited to conceptualise the design of a gamified MOOC using, based on their experience, the most suitable game elements to gamify it in order to enhance users' learning performance (p1); goal achievement (p2) or engagement (p3). Each purpose was chosen by two of the six groups, respectively. The topic of the MOOC was given as cyber-security. Each group elaborated a presentation that was performed to the other game designers.

The first two groups that conceptualised the gamification design related to $\mathrm{p} 1$ (learning performance) identified the following game elements: Group 1 proposed to use: collaboration via wiki and forum, aiming at developing a sense of community and information sharing, track of personal progress, levels and different levels of tasks, with a rewarding system for their completion and an inventory for personal notes, in which to save helpful posts from the community forum; they also thought of implementing a game itself within the MOOC. Group 2 proposed to aim at allowing users to follow an autonomous path, as well as a collaborative path, that could be enabled by the creation of alliance, asymmetrical information distribution for the solution of boss tests. In addition, group 2 suggested including several levels within the MOOC and a skills tree ${ }^{2}$ which is a game element often present in roleplaying games, (the Diablo ${ }^{3}$ series made it famous) and it enables custom configurations of a character's abilities.

\footnotetext{
${ }^{2}$ It is called a tree because once the basic skills are gained by the users, it opens several branches and the user can decide what to follow.

${ }^{3}$ Blizzard production, 1998. http://eu.blizzard.com/en-gb/games/
} 
Another two groups $(3,4)$ conceptualised the following game elements for the $\mathrm{p} 2$ (goal achievement): Group 3 proposed "personal profiles that can be shared with others, badges as rewards, progress bar and autonomy". Group 4 came up with the following idea of transferring the Massive Multiplayer Online Games (MMOG) elements into MOOC, such as: Skill tree, connected with the learning needs, learning content and tasks, with a test after each MOOC; "Knowledge inventory (completed tasks for the course); Overview (whole offer, progress per Skill tree); Co-op (Cooperation with "Classes"); PVP (Player vs. Player "Knowledge Battle"); Reward inside of System (Skill tree, Knowledge Inventory, Succeeded Students as mentor for newbies); Reward outside of Systems (Achievements, Link to LinkedIn)".

The last two groups $(5,6)$ of game designers worked on the conceptualisation of a gamified MOOC for p3 (engagement). Group 5 proposed the use of competition, collaboration and immediate feedback as game elements to enhance user engagement. They suggested integrating a game concept similar to QuizClash in a MOOC platform: an online quiz game for two players, where one player chooses from several categories and challenges a friend. Both receive the same question and the one who replies faster and correctly wins. The game element was chosen because activating social comparison could engage students. Group 6 proposed using the following game elements to enhance users' engagement in MOOCs: Quests, Narrative, Player/Character, Enemy/Boss, Community (Guild)/Community Experience and Status Parameter. In particular, the narrative conceptualised consists of "some sort of opposing power that threatens the participants" characters and their private information". In this framework, the participant goal is to work against this power to protect his/her own identity. The players will work together cooperatively against the system and develop a resistance force. As one of the participant states: "The player needs to use what $\mathrm{s} /$ he learns in the modules of the course to contribute to the success of this resistance". Being part of this resistance could help in developing "a sense of community similar to MMORPG (Massive Multiplayer- Online Role Play Games) communities such as guilds". "Even if participants are working alone, they should feel that they are contributing to the cause of the resistance/ the community", therefore collaboration has to be an option and "it will not be enforced".

Hints from Learning Scientists and TEL Experts. Learning Scientists (LS) as well as TEL experts were not involved in focus groups, however they could express their point of view through the use of the open questions contained in the survey that asked them to detail the advantages and disadvantages of using a specific GDP for the purpose selected. Selected comments are reported here to give a better overview of the LS as well as TEL experts' perceptions on gamification applied to MOOCs.

LS experts gave the following feedback on the three purposes: Starting with the p1 (learning performance), the most rated GDPs were Levels, Empowerment and with equal score Avatar/Characters, Storytelling and Clues. The advantages listed for these were: "Levels give structure in the learning"; Empowerment was appreciated because "people like to have autonomy". Avatar allows "higher identification with the MOOC", as for Storytelling: "Human beings think in the shape of stories, I would guess it clearly enhances performance if done in a way that people can make a meaningful connection with the story" that has been told. Lastly, Clues given only at request ("hints button") "could be useful". With respect to p2 (goal achievement), the highest scores recorded were for the following GDPs: Smooth Learning Curves and the equally scored Clues and Empowerment. LS declared that Smooth Learning Curves gave the chance to users to track and "experience progress in learning", as for Clues, these can work as "scaffolding for learners who need a little more support, 
through clues everybody can achieve their goals", as disadvantages foreseen: "If it is too easy to obtain clues, the students might not try to figure things out themselves". Regarding Empowerment, "it can help users to positively achieve their learning goals". Aiming at p3 (engagement) for LS, the GDPs: Storytelling, Clues and Engagement received the highest scores and the only one commented on was Clues: "It helps to have clues, especially for complex goals. However, having them pop up can also distract" the users and be a disadvantage.

TEL experts detailed the following advantages and disadvantages of each GDP for the specific purposes: Starting with p1 (learning performance), the GDPs with the highest ranks were Levels, Smooth Learning Curves and with equal score Storytelling, Replayability and Empowerment, commented as follows: "Levels on the one hand can add motivation to the users (positive) but on the other hand, depending on the users, having several levels to overcome might increase the pressure on the users", "if combined with time restriction, this might result in negative effects", "levels can help to monitor progression", "as disadvantages - they would work in long and complex scenarios, which is something to be considered in the MOOC design". With reference to Smooth Learning Curves, TEL experts say: "If a learner is an international learner who struggles with language or a novice learner, it may help them through the course"; "apparently only for experts this is not a good strategy, for novices and intermediate learners this should work". About Replayability, it can facilitate "learning by failure", anyway it should be given as an option and it "can support the mastering of the learning". As to Empowerment advantages: "it can improve engagement" while as a disadvantage it is "often over engineered (serious games), it might lose credibility".

Looking at p2 (goal achievement), the GDPs that recorded the highest scores were Goal Indicators, Levels and, with an equal score, Replayability and Smooth Learning Curves. The comments provided by TEL experts on Goal Indicators were that it "provides useful insight about a learner's performance and may set the pace of the learning progress, it could especially be useful "as goals might change over time". Concerning Levels, an advantage found by TEL experts was: "they can offer flexibility for learners to perform in conditions where they can achieve 'flow' and also set a degree of challenge", however if "the levels of difficulties are badly designed they might affect the learning process" and performance. A disadvantage reported for Replayability is that "it might offer learners a way to trick the system into getting higher scores or obtain other rewards", it could however have the advantage of "leading learners to master the concepts". For Smooth Learning Curves, the advantage of "avoiding discouragement" among users was reported.

The GDPs Communication Channels, Score, Goal Indicators, Cooperation and Smooth Learning Curves were selected by TEL experts for p3 (engagement). Comments for Communication Channels state that "it is very important to have multiple communication channels to suit different target audience needs. It helps users to feel connected and avoid a sense of isolation"; "Learning is more effective when we engage with peers, so any element to sustain this social component could help if it is used in the right manner". Regarding Score: a "personal score system could work in the same way as levels. It helps compete with yourselves rather than others". As for Goal Indicators considering that "the success is not defined in MOOCs. One might want to finish only the two weeks that they are interested in. So, if that person puts those goals beforehand, completing them makes that person successful in the course. I think this is very much suitable for the nature of MOOCs". While Cooperation on the one hand "can increase engagement", on the other hand 
"some users will rely on others to reduce effort", it is likely that "it won't help low engaged learners". Lastly, Smooth Learning Curves could have as an advantage the decrease of users' "frustration and boredom" but as a disadvantage the TEL experts raise the problem that it is "hard to design".

\section{Discussion and Conclusion}

Investigating the point of view of game designers, learning scientists (LS) and TEL experts on the selection made on Björk and Holopainen's collection, allows us to understand that despite the different backgrounds of our study participants, there are several points of agreement. With the purpose of identifying suitable GDPs to design our gamification strategy to be applied in a MOOC to enhance users' goal achievement and engagement, we analysed the literature and due to the lamented simplicity of the game elements used up to now and the scarce availability of empirical studies of gamification applied to MOOC, we decided to query other sources, such as those mentioned above [6].

By analysing the data gathered from the questionnaire, it is possible to deduce that among the game designers a common agreement on the evaluation of expected effects of determinate game design patterns within a MOOC for a specific purpose can be recorded. The game designers, for all three purposes, evaluated with a high rank the GDP Communication Channels. While Smooth Learning Curves was the GDP that received unanimous consensus, but it was selected for only 2 purposes by the game designers, p3 and p1. The LS indicate with a high score the GDP Clues for the three purposes; what is more Empowerment and Storytelling received a high score from the LS but only for the p1 and p2, not for p3. The TEL experts ranked the GDPs: Smooth Learning Curves with a high score for all 3 purposes; and Goal Indicators for only the purposes $\mathrm{p} 2$ and $\mathrm{p} 3$.

Considering the similarity between the groups in ranking the GDPs, game designers and LS both chose the GDP Empowerment for $\mathrm{p} 2$ and related to the $\mathrm{p} 1$ and p3 there is not a recorded similarity in the GDPs selected. Game designers and TEL experts issued high ratings related to $\mathrm{p} 1$ for the GDP Smooth Learning Curves; to p2 purpose for Goal Indicators and to $\mathrm{p} 3$ for Communication Channels and Smooth Learning Curves. Comparing LS and TEL experts, on p1 they both rated the GDPs: Levels, Empowerment and Storytelling highly. While for p2 TEL and LS experts ranked the GDP: Smooth Learning Curves highly. As for p3 there are no common GDPs with a high score.

With the analysis of the qualitative data we could report and have more clues on the reasons for the scores given as well as having a deeper understanding of the game designers' intention in choosing (or not) a specific pattern for a defined purpose and application. A precious contribution came from the focus group of the game designers with almost a continuous reminder of MMORPG.

Based on this study, our first step towards implementing gamification in MOOC can be concluded by identifying the following GDPs as candidates for further investigation in a field study with the purpose of empirically testing whether the designers' intentions match the effects on users' behaviour stimulating the desired effects or not. Specifically, the GDPs eligible for our implementation are (1) Empowerment, (2) Smooth Learning Curves (3), Communication Channels, (4) Levels, (5) Clues, (6) Goal Indicators, (7) Skills tree; (8) Guild and (9) Storytelling. 
As the next step, we will design, run and evaluate empirical experiments based on these results.

Acknowledgements. This study is partly funded by the I SECURE - Empowering education systems in information security project (n. 2015-1-IT02-KA201-015005) under the Erasmus+ programme of the European Commission (http://www.isecureedu.eu/index.php/en/). We would also like to thank the participants who voluntarily took part in this study. A summary of these data can be found in [7].

\section{References}

1. Dicheva, D., Dichev, C.: Gamification in Education: Where Are We in 2015? In: E-Learn 2015 - Kona, Hawaii, United States. pp. 1445-1454 (2015).

2. Dicheva, D., Dichev, C., Agre, G., Angelova, G.: Gamification in Education : A Systematic Mapping Study Gamification in Education : A Systematic Mapping Study. Educ. Technol. Soc. 18, 75-88 (2015).

3. The Right to Education I Education I United Nations Educational, Scientific and Cultural Organization, http://www.unesco.org/new/en/right2education.

4. Antonaci, A., Klemke, R., Stracke, C.M., Specht, M.: Gamification in MOOCs to enhance users' goal achievement. In: Proceedings of IEEE Global Engineering Education Conference (EDUCON 2017), 25-28 April, Athens Greece. IEEE Xplore.

5. Chang, J.W., Wei, H.Y.: Exploring engaging gamification mechanics in massive online open courses. Educ. Technol. Soc. 19, 177-203 (2016).

6. Björk, S., Holopainen, J.: Patterns in Game Design. (2005).

7. Antonaci, A., Klemke, R., Stracke, C.M., Specht, M.: Identifying game elements suitable for MOOCs. In: Lavoué, É., Drachsler, H., Verbert, K., Broisin, J., and Pérez-Sanagustín, M. (eds.) Proceedings of the 12th European Conference on Technology Enhanced Learning. pp. 355-360. Springer Lecture Notes in Computer Science (LNCS) series., Tallinn (Estonia), 12 - 15 September 2017 (2017).

8. Lundgren, S., Bjork, S.: Game mechanics: Describing computer-augmented games in terms of interaction. In: Proceeding of Technologies for Interactive Digital Storytelling and Entertainment (TIDSE). , Darmstadt, Germany (2003).

9. Antonaci, A., Klemke, R., Specht, M.: Towards Design Patterns for Augmented Reality Serious Games. In: Bown, T. and van der Merwe, H. (eds.) The Mobile Learning Voyage From Small Ripples to Massive Open Waters. Communications in Computer and Information Science. pp. 273-282. Springer, Cham (2015). 